\title{
Nothing is something: on The Disappearing of Vincent Gambini
}

\section{Augusto Corrieri}

University of Sussex

\begin{abstract}
This article describes and examines a recent film about a cancelled theatremagic show, with reference to a few significant artists working in visual art and cinema. The film in question, The Disappearing of Vincent Gambini (2021) by Augusto Corrieri and Hugo Glendinning, came about in response to the closure of UK theatres at the start of the pandemic in 2020. The article, written by one of the film's makers, details the process that led to the collaborative work; it then focuses on two key scenes from the film, and discusses these in relation to the works of $20^{\text {th }}$ and $21^{\text {st }}$ century artists, including Chantal Akerman, Tacita Dean and Robert Rauschenberg. What emerges is an understanding of how artistic processes can embrace and work with disappearance and erasure; the essay concludes by proposing that amazement and wonder might lie less in the execution of successful magic, but rather in a mode of perception attuned to the present, whatever it may hold.
\end{abstract}

\section{KEYWORDS}

Magic, film, presence, absence 


\section{INTRODUCTION}

Let's begin with an academic digression - the only one in this otherwise informal essay - to help explain the title.

One of the academic debates that has dominated the fields of theatre and performance studies, across the last 20 years or more, is the one revolving around disappearing versus remaining. The question is whether performance disappears - its value and purpose intimately bound up with its irredeemable loss - or whether performance in fact remains: embodied, archived, remembered or recorded, performance continues to re-appear. ${ }^{1}$ If initially the academic consensus championed performance's disappearance, the last decade has seen a shift towards the opposite pole (buoyed no doubt by the increasing pervasiveness of the camera and digital recording).

This debate has perhaps obscured a rather simple fact: that performance's disappearing and remaining function together, like two sides of the same coin, spinning in mid-air. Performance, like this very moment of reading, disappears-remains-disappears-remains-disappears... It is this strange flickering of presence and absence that seems to be at the heart of performance (as well as much else).

As an artist working across theatre, performance art and magic, I have been drawn, for several years now, and often without being able to name it, to the particular charge we might find in and around the absent event: the lingering of the no longer here, the promissory force of the empty room, the empty theatre. My three-word art manifesto would be, simply: nothing is something.

\section{THE FILM}

Across 2020-2021 I collaborated with UK photographer and video maker Hugo Glendinning to realise a short film (35mins) entitled The Disappearing of Vincent Gambini. The film was made in direct response to my own theatre show, whose 2020 England tour was cancelled due to the pandemic: the show in question was The Chore of Enchantment by Vincent Gambini, Gambini being the magician pseudonym I use to present theatre-magic shows. The Chore of Enchantment's (semi)fictional conceit centred on Gambini the magician being overwhelmed by global news events - Brexit, Trump's election, climate breakdown, etc. After several tricks involving cards, coins, canes, a rope and a handkerchief, he confesses to the audience that he finds it impossible to carry on doing something as futile and escapist as a magic show: Gambini collapses on stage,

\footnotetext{
${ }^{1}$ The chief theoretical works that spurred and framed this debate within performance studies were Peggy Phelan's 1993 Unmarked: The Politics of Performance and Rebecca Schneider's 2011 Performance Remains: Art and War in Times of Theatrical Reenactment.
} 
quits the show, and magic altogether. Briefly, that was the show's premise: a magician experiencing an existential crisis about his craft, yet still performing deceptive feats of wonder along the way. ${ }^{2}$

The Chore of Enchantment began its tour in England in Spring 2020 (a previous version of the show had been presented at a few theatres, including in 2018 at the Edinburgh Fringe Festival). When the pandemic hit the UK, in March 2020, and it became obvious the show's tour would be cancelled (only 2 out of the 9 scheduled performances went ahead), I realized the irony of the situation: the show that Gambini claimed was impossible to perform (because of global news events) had now become genuinely impossible to perform (because of global news events). The fictional cancellation had become all too real.

Furthermore, the show, in its 'final' version for the 2020 tour, was never recorded, meaning there was no video documentation of a performance I'd spent 5 years developing.

In May 2020, after the initial shock and confusion of the lockdown, and wanting to put the remaining Arts Council England touring funding to good use, I gradually set on the idea of making a film of, or about, The Chore of Enchantment. But what would the film's aim be, I wondered? Would I want to somehow 'save' the performance from disappearing?

\section{ERASURE}

Despite an initial temptation to try and make a film that would capture or 'save' the cancelled show, to produce a permanent record of it (for example by arranging to have the whole show recorded inside an empty theatre, or perhaps adapt it for a Zoom audience), the approach Glendinning and I took was instead to embrace and work with the show's cancellation: our material was now the erasure, the disappearance, and the 'nothingness' left in the wake (remember: nothing is something). What comes to mind is a canonical work of conceptual art by Robert Rauschenberg, Erased DeKooning (1953).

\footnotetext{
${ }^{2}$ As an extra 'layer' to the performance's narrative, there was a Borgesian (or Kaufmanesque) paradox, revolving around a show-within-a-show premise: it gradually becomes clear that the whole show is in fact a memory which Gambini is playing out in his mind, over and over again, as a form of therapy, to try and process this last dreadful performance, and hopefully find a reason to perform magic again. The show itself happened in the mind of the magician, both in the past and the present.
} 


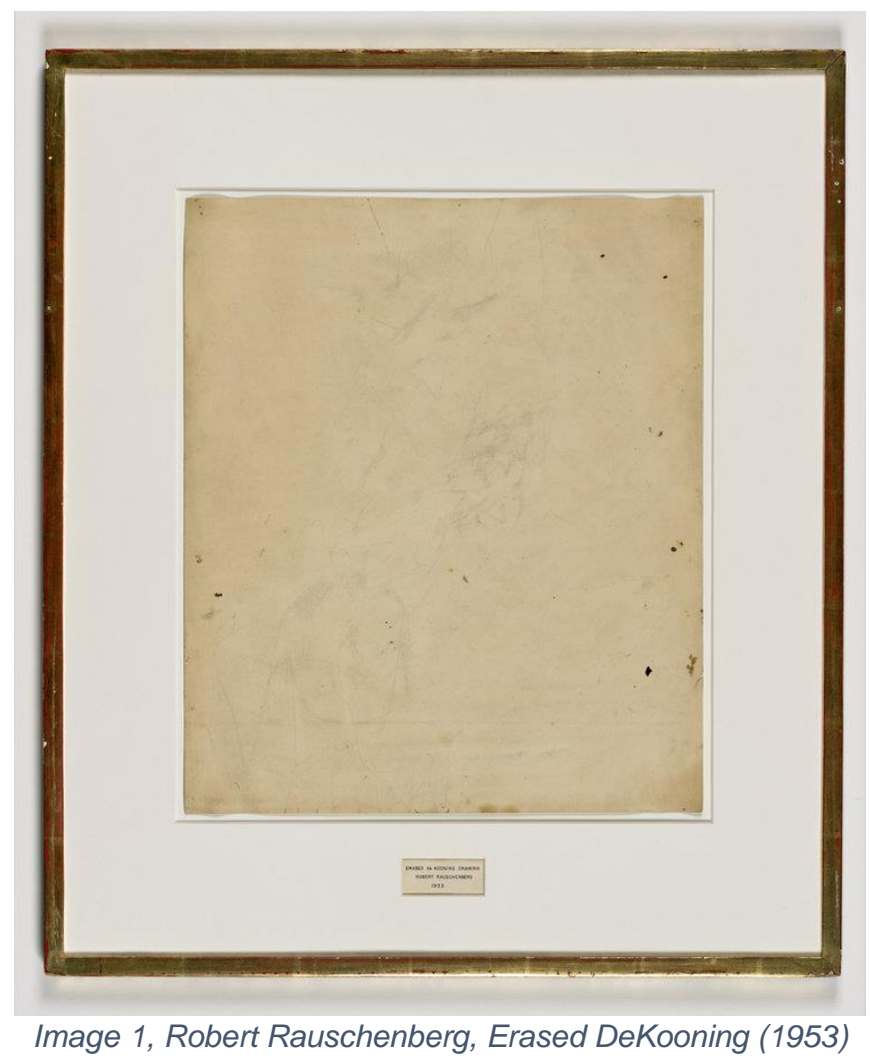

The work consisted in Rauchenberg convincing one of the most prestigious US visual artists of the time, Willem de Kooning, to give him a drawing; Rauschenberg then proceeded over several weeks to carefully erase the work, finally producing a largely blank sheet of paper, the barest of traces and marks still visible. Erasure, it seems, is not the opposite of art, but rather one of its modes.

Roughly echoing Rauschenberg's approach, the aim of the film became, quite simply, to produce a new work (the film) through the erasure of another (the performance).

The ambition was therefore not to save or record The Chore of Enchantment, but rather to chart and explore its erasure; and to embrace (if embracing is at all possible) this suspension or interruption of theatre, at a time, in the Spring of 2020, when so much was being suspended and interrupted. Instead of 'The Show will go on', as several large posters outside boarded-up theatres hopefully proclaimed during the lockdown, a guiding ethos of our project might have been: 'No, the show cannot go on. It must not go on. There is no way the show is going on. Instead, let's make a work from the absence of the show.' 


\section{PUTTING THE REHEARSAL ON SHOW}

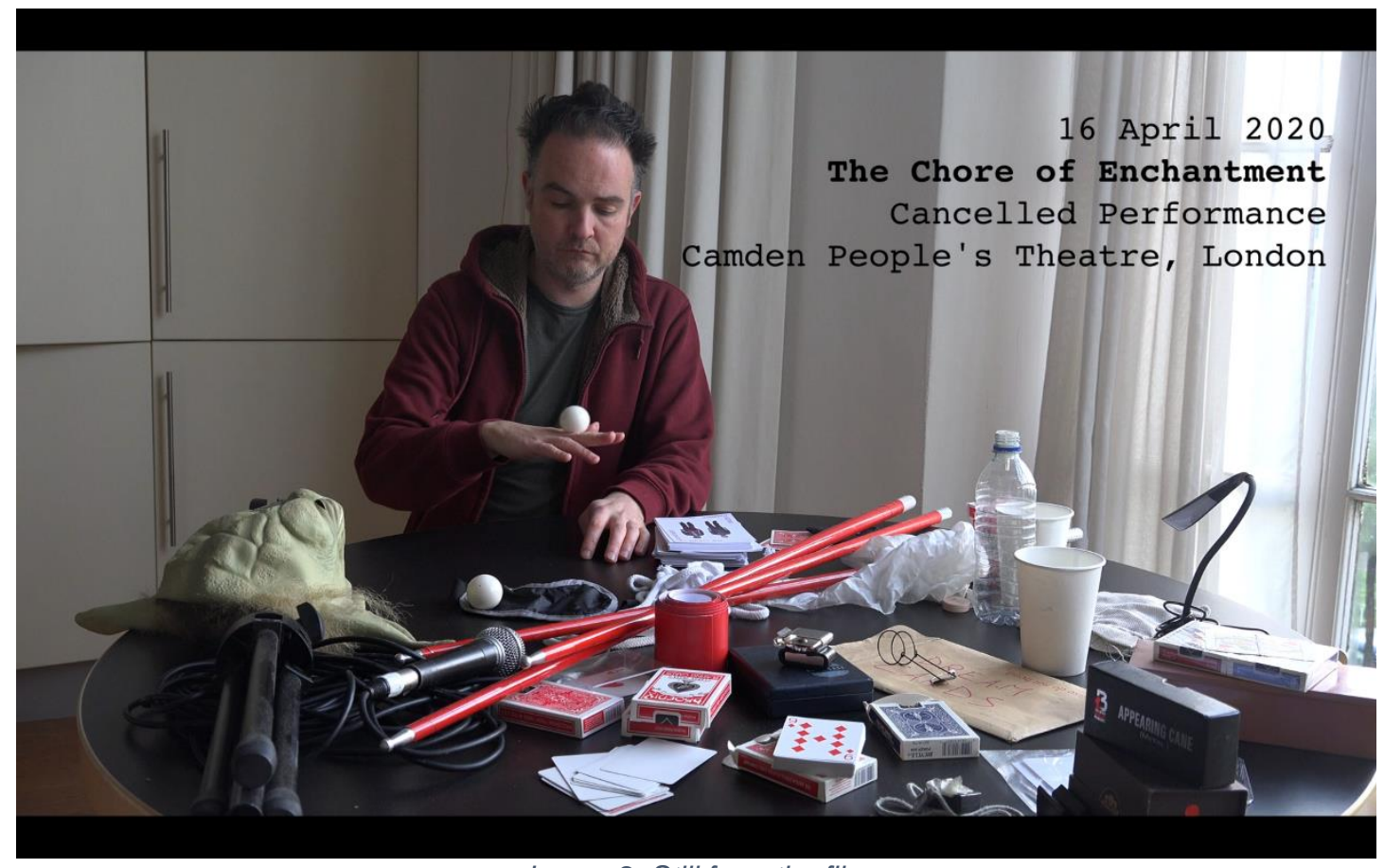

Image 2, Still from the film

The film has a simple temporal structure, stretching over a 4-month duration (March to June 2020), pinpointed by the dates and venues of the cancelled tour e.g. $15^{\text {th }}$ April, Camden People's Theatre, London. On each tour date, I can be seen briefly in my flat in Brighton, UK, sitting at a table, gazing down at the show props that now lie scattered and useless, 'objects without purpose'; or rather, as I reflect in the film (in a recorded phone message to Glendinning), the prop's purpose has shifted: through their inactivity, they have become powerful reminders to focus on what really matters, in the midst of a pandemic (and always): caring for others and oneself, for family members, friends, and strangers.

Broadly speaking, the film begins inside, in the flat, and gradually moves outside, on the streets of Brighton: a central component is the phone dialogue between myself and Glendinning the film maker, presented in the mode of a documentary.

Instead of describing the whole film, I am going to focus on two sections, and reflect on how they connect to larger issues around magic performance, labour, and 'nothing happening'.

The first is a sequence composed of extracts of private rehearsal videos: made over the last 5 years, these videos were never meant to be shared with anyone, since their purpose is purely practical: like a mirror, they are simply a way for me to test the handling and sleight-of-hand as it develops. In the context of the 
film, however, this assembled sequence of private rehearsal videos sheds some light on the otherwise unseen labour that sleight-of-hand magicians undertake: viewers are invited to observe the hidden practice that sustains and underpins the performance (the performance only being the tip of the iceberg). Like solo musicians, magicians spend much of their time alone, refining their skill in the handling of objects so as to produce the illusion that, oddly, no skill or special handling is in play: in other words, magic occurs through hiding the labour that produces it. ${ }^{3}$ It felt relevant, in a film exploring a cancelled magic show, to draw back the curtain and display footage that I had never shared with anyone (since these videos are quite literally addressed to me).

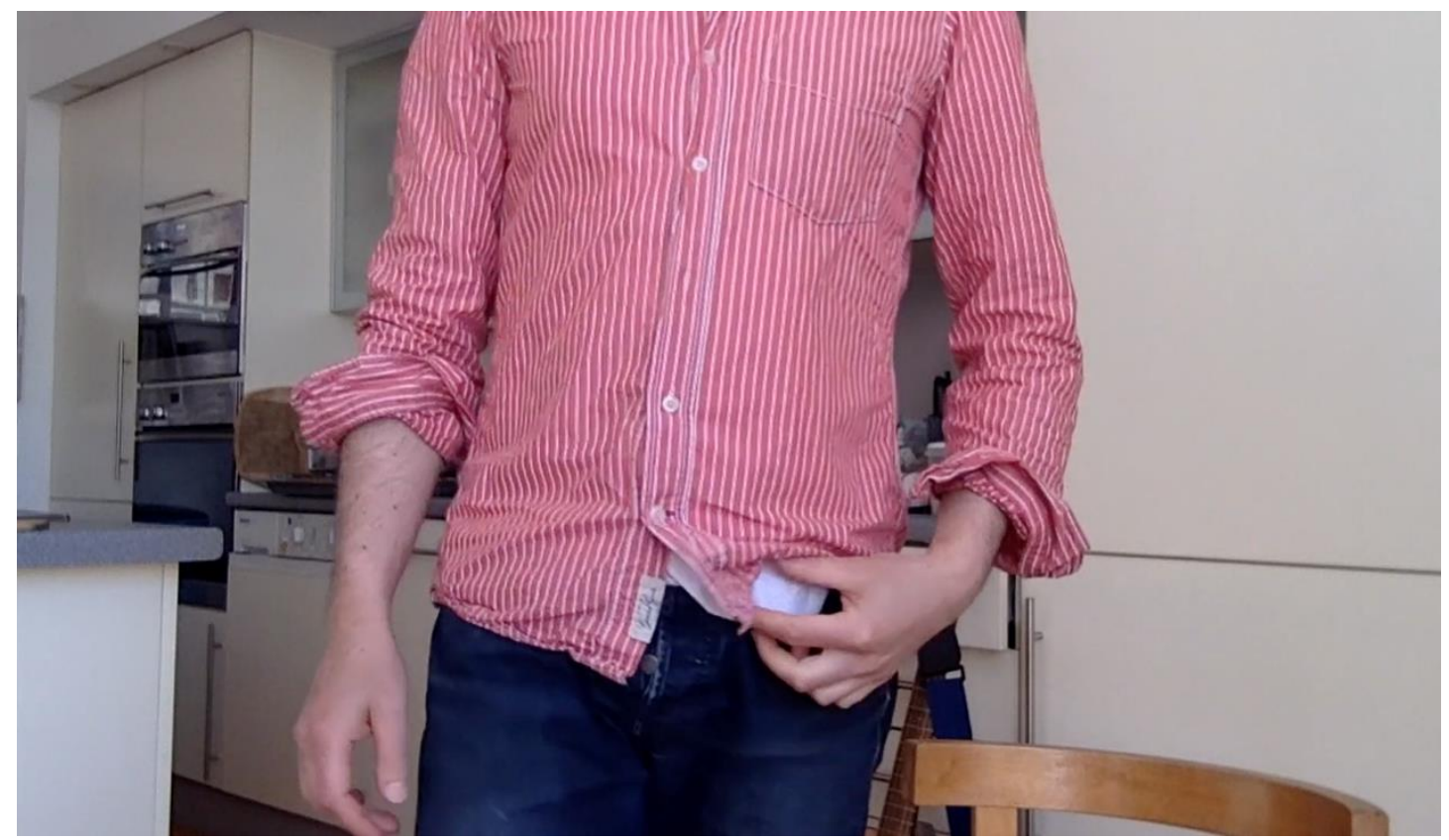

Image 3, Still from the film

The videos move between the cryptic and the accessible: at one point, I am seen practicing a sequence of card magic, all the while naming out loud the particular sleights or techniques: injogging a card, doing a triple, a top change, a spread pass. Audiences get a peek into the peculiar terminology of card magic, without knowing what the terms refer to, or what they even are. At other times, there are glimpses into the actual working methods, as when I repeatedly practice 'stealing' (taking) a coin from my left hand into my right: the hope is that in the context of the film, this exposure, which is normally a taboo in the world of magicians (secrets must be preserved, or else), might allow audiences to better understand and appreciate the otherwise unseen

\footnotetext{
${ }^{3}$ This isn't a 'universal' statement about magic, but rather an approach popularised in the 1950s by Dai Vernon in the US. Vernon taught generations of sleight-of-hand magicians to work towards 'naturalness', eliminating quick or suspicious movements in favour of an unhurried and seemingly open mode of performance. See for instance Ganson, 1996.
} 
labour of magic. Counterintuitively, the exposé of secretive mechanics works to invite wonder and appreciation of sleight-of-hand (not to spoil or ruin it). Taking a step back, here the erasure of the main work - the touring show makes room to showcase something else: the private sketchbook, the preparatory notes. The personal rehearsal videos are assembled and framed as part of a new artwork; that which is in the wings is moved centre stage, since the main player has left.

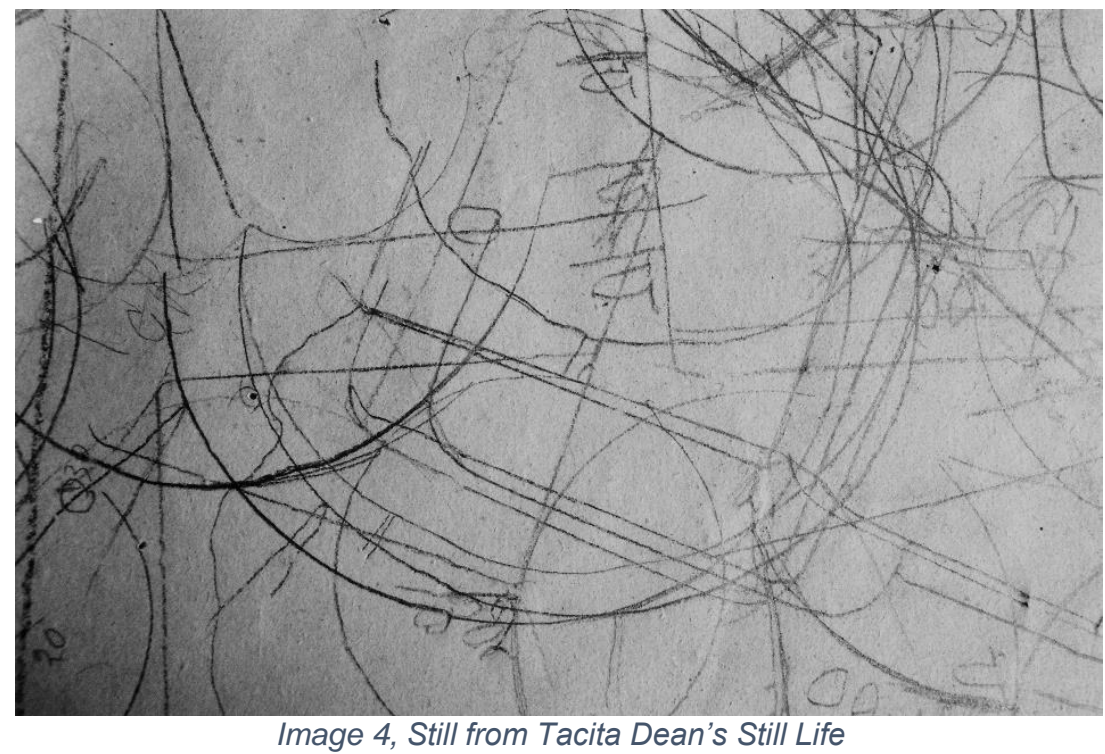

I'm reminded here of UK artist Tacita Dean, specifically her film of the markings and measurements made by Italian painter Giorgio Morandi on the cheap paper upon which he would place bottles and other objects for his paintings; originally serving a purely practical function - to determine the arrangement of objects (like the marks on a stage that performers need to find their position) - this secondary material from Morandi's painting studio becomes the central focus in Dean's film Still Life (2009). This is what erasure makes possible: the irrelevant becomes relevant. What is behind or beneath the art now becomes the art.

\section{TO SEE WHAT'S HERE, VIA CHANTAL AKERMAN}

The second section I want to reflect on is the central scene in the film, consisting mainly of static shots of Brighton's closed and empty shops during lockdown. Before describing this, I want to first consider the scene's inspiration or predecessor: Belgian filmmaker Chantal Akerman's quietly engrossing News from Home (1977), which features long takes of empty New York streets and cafes, gradually filling with people, while the director's voice is occasionally layered on top, reading letters from her mother. 


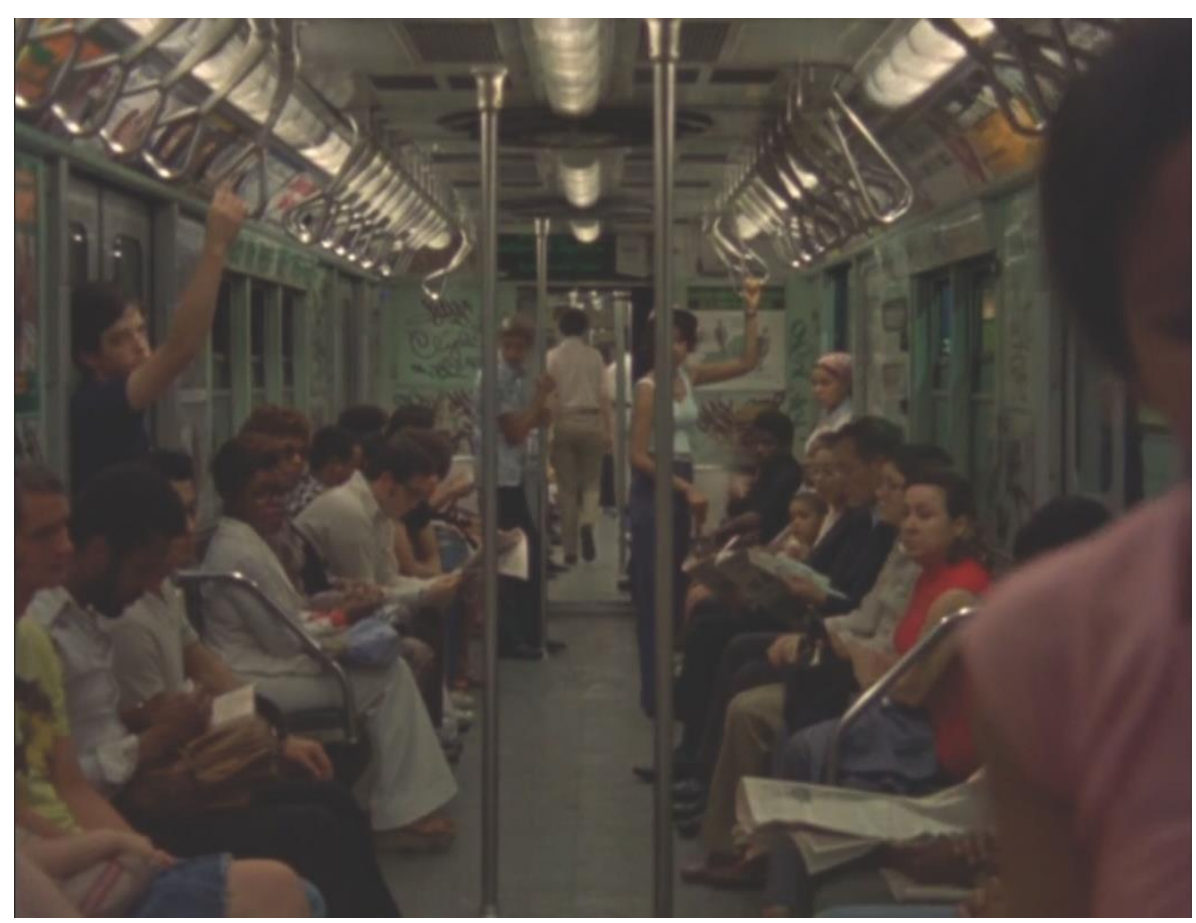

Image 5, Chantal Akerman's News from Home

Despite nothing happening (or perhaps because of it), there is a disquieting quietude in Akerman's film: a disarming patience, an energised deflation, that invites lingering on simply what is present or presented: a passer-by, the colour and texture of a building, the way the city appears as a world of stillness and motion, people, light, and darkness. There are few real surprises or 'events', in any traditional sense, in Akerman's long static takes; rather, I would say, the event is the watching itself: what the film energises and liberates are our own ways of seeing and attending to so little and so much happening. As the film unfolds, it invites us (if we accept this invitation) to practice actively observing, listening, waiting, looking; in this way, the viewer's experience is placed centre stage: I oscillate between engagement, boredom, finding my interest, losing it, refinding it etc. This is where the real event happens, in the watching itself. We could say that this is always the case - since the world is not objectively 'out there', it is always a result of our own cognitive elaboration, interpretation, etc. Yet in Akerman's case this basic perceptual and cognitive premise is amplified, allowing us to experience our own looking. I become aware, watching these long takes of New York in the 1970s, how much my perception is transformed: ordinary streets and sights appear somewhat extraordinary or wondrous, and this transformation (at times so subtle it's imperceptible) occurs through a kind of giving up, of expectation, of desire even: a renunciation of mastery that is in some ways the opposite of magic (if we can define magic, somewhat narrowly, as illusive mastery over matter, the imposition of one's will on things). In Akerman's film, things just are as they are, and with the right attention, an oddly affective quality of presence and being seems to emerge. It's as though 
all hierarchies of value had been eroded or flattened, and we could start attending to the world, to the visible, anew.

Perhaps a popular filmic example of discovering awe through an act of sustained attention might be the infamous floating plastic bag in American Beauty, though here, ironically, the desired affect is heavily managed, or forced, through sentimental music and an overpowering speech about transcendental awe in the face of ordinary phenomena.

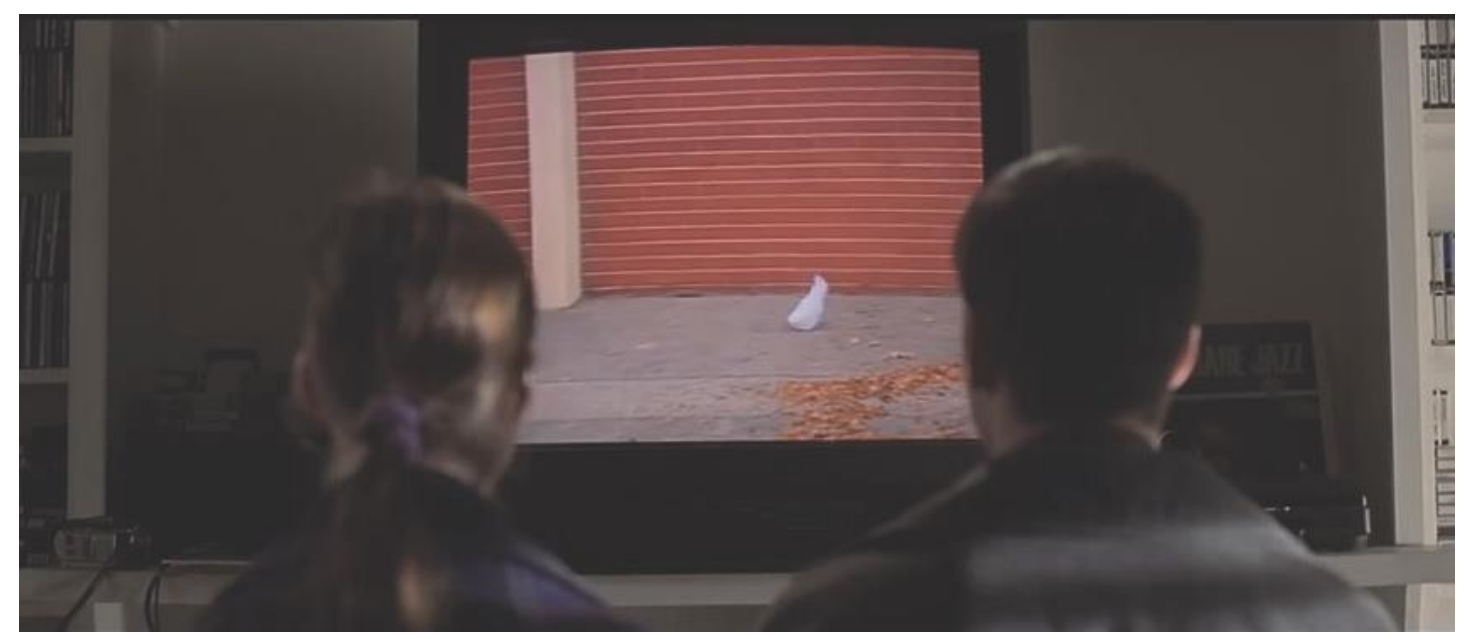

Image 6, Still from American Beauty

To return to The Disappearing of Vincent Gambini. For the central scene, we combined static takes of Brighton's empty shops during the 2020 lockdown with the audio from a 2018 recording of The Chore of Enchantment at the Edinburgh Fringe Festival, in particular a 5-minute rope trick performed to a gentle jazz piano track. In the film we don't of course see the rope trick: we hear the music and, crucially, the live Edinburgh audience responding with laughter and applause, which plays on top of the footage of empty Brighton shops and their reflective glass fronts. Here the interest was less in the perhaps obvious contrast between the lifeless shop and the sound of live audiences in performance, and more in how the sound could subtly frame and amplify visual elements: the music and laughter of the live act function as counterpoint, allowing the audience to linger for 5 minutes with scenes in which very little happens: a closed café, a flower shop, an empty barber's, and spaces that have been cleared, or boarded up.

At times, the clapping and laughter of the audience at the Edinburgh show coincide (I want to say, as if by magic) with small 'micro events' in Brighton, usually reflected in the glass of the shop windows, which become a kind of stage or screen or canvas. And so, a scattering of applause accompanies the reflection of cyclist whizzing past the flower shop; a shirtless man is greeted 
with laughter as he walks past a café; skaters doing tricks in the window of a closed Zara store similarly get applause and laughter for their tricks.

At one point, as though unintentionally evoking American Beauty, we watch a white napkin, reflected in the window of a shoe shop, gently buffeted by the wind, as the audio again plays the jazz tune and audience laugh. We know the audience reaction isn't directed at the napkin, and yet, in the film, it becomes so: the audio gently underlines the micro-event of the drifting paper napkin, highlighting that another audience - the film audience - are now being asked to attend to, and be present for, the smallest events.

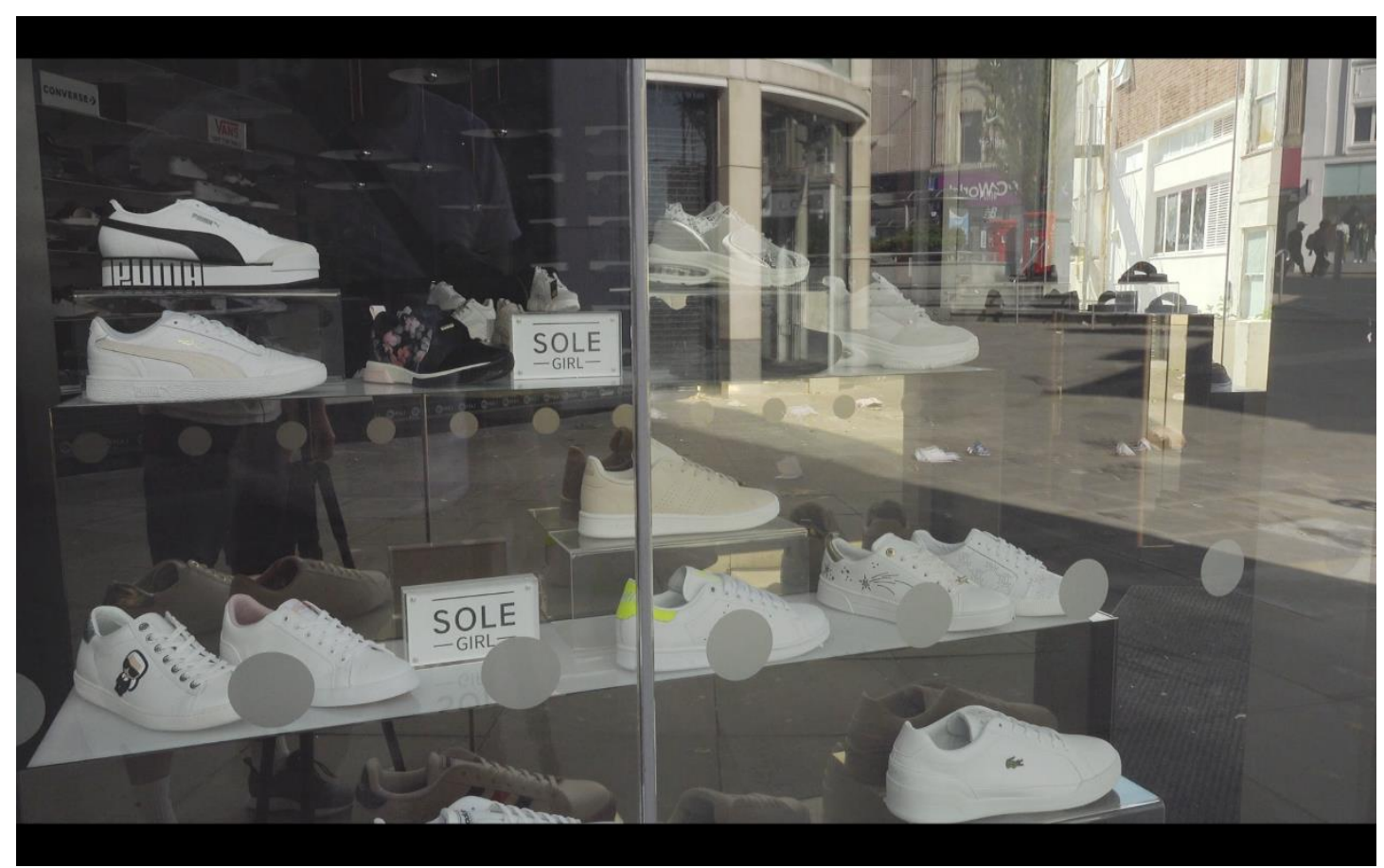

Image 7, Still from the film

The stage performance is unavailable - it has disappeared - but its 'secondary' material, in this case the sound of audiences reacting to the magic trick, is here used as primary material for a new work. The audience's gasps and applause now accompany the simple presence and movement of people and objects in the streets of Brighton. The scene's invitation - for whoever wants to accept it - is to (re)discover the ability to simply be present to whatever happens to happen; and, in the context of a pandemic, having a space to practice such a mode of attention seems suddenly all the more necessary. In his book The Long Take: Art Cinema and The Wondrous, film theorist Lutz Koepnick writes about films that linger, often in stillness and extended duration: here the intention is to 'make us probe our economies of attention and preserve the promise of a world in which we may recuperate our ability to be amazed by something that unexpectedly presents itself to our eyes.' 
(2017, p. 16) The Disappearing of Vincent Gambini was a work that hoped to share in this promise, this rehabilitation of perception, and the possibility of being amazed, not by the illusion of impossibility, but by the most ordinary things around us.

Perhaps novelist Don DeLillo put it best, when describing a desired type of spectatorship:

'To see what's here, finally to look and to know you're looking, to feel time passing, to be alive to what is happening in the smallest registers of motion.'

\section{REFERENCES}

Corrieri, A. \& Glendinning, H. (2021), The Disappearing of Vincent Gambini DeLillo, D. (2010), Point Omega. London: Picador.

Koepnick, L. (2017), The Long Take: Art Cinema and The Wondrous. London: University of Minnesota Press.

Phelan, P. (1993), Unmarked: The Politics of Performance. London: Routledge. Rauschenberg, R. (1953), Erased DeKooning, San Francisco Museum of Modern Art.

Ganson, L. (1996), Dai Vernon's Inner Card Trilogy. Bideford, L\&L Publishing. Dean, T. (2009), Still Life. Frith Street Gallery, London, and Marian Goodman Gallery, New York/Paris.

Akerman. C. (1977) News from Home, France.

Mendes, S. (1999), American Beauty, US: DreamWorks Pictures.

Schneider, R. (2011), Performance Remains: Art and War in Times of Theatrical Reenactment. London: Routledge. 